\title{
False context fear memory in rats
}

\author{
Sarah E. Bae, Nathan M. Holmes, and R. Frederick Westbrook \\ School of Psychology, University of New South Wales, Sydney 2052, Australia
}

\begin{abstract}
Four experiments used rats to study false context fear memories. In Experiment 1, rats were pre-exposed to a distinctive chamber (context A) or to a control environment (context C), shocked after a delay in a second chamber (context B) and tested either in B or $A$. Rats pre-exposed to $A$ froze just as much as control rats in B but more than control rats in A. In Experiment 2, rats were pre-exposed to $A$ or $C$, subjected to an immediate shock in $B$ and tested in $B$ or $A$. Rats pre-exposed to $A$ froze when tested in $A$ but did not freeze when tested in $B$ and control rats did not freeze in either $A$ or B. The false fear memory to the pre-exposed A was contingent on its similarity with the shocked B. In Experiment 3 , rats pre-exposed to $A$ and subjected to immediate shock in $B$ froze when tested in $A$ but did not freeze when tested in $C$ and rats pre-exposed to $C$ did not freeze when tested either in $A$ or $C$. In Experiment 4, rats pre-exposed to $A$ and subjected to immediate shock in $B$ froze more when tested in $A$ than rats whose pre-exposure to $A$ began with an immediate shock. The results were discussed in terms of a dual systems explanation of context fear conditioning: a hippocampal-dependent process that forms a unitary representation of context and an amygdala-based process which associates this representation with shock.
\end{abstract}

Rats learn to fear a context (a distinctive chamber) in which they receive brief but aversive footshock. This learning is thought to involve two distinct systems. The first, hippocampal-dependent system records the conjunctions among the array of cues (the surfaces, texture of the floor, shape, and so on) and combines this information into a unitized representation of the context (e.g., McLaren et al. 1989; Sutherland and Rudy 1989; Fanselow 1990; O'Reilly and Rudy 2001). The second, amygdala-dependent system forms excitatory associations between this unitized representation of the context and the fear motivational system elicited by the aversive shock unconditioned stimulus (US). The consequence of these associations is that rats exhibit fear responses when re-exposed to that now conditioned context (e.g., Davis 1990). The interaction of these two systems explains the relation between the levels of context conditioned fear responses and the interval of time between placement in the context and the occurrence of shock. These levels are directly related to that interval (Fanselow 1986; Kiernan and Westbrook 1993). Specifically, rats shocked a few minutes after placement in the context exhibit substantial levels of fear responses (e.g., freezing) because they had sufficient time before the shock to form the unitary representation required for context fear conditioning. Conversely, rats shocked at shorter placement-intervals freeze progressively less as the interval decreases. Indeed, rats shocked immediately on placement into the context exhibit little or no freezing — they exhibit the so-called immediate shock fear deficit (Fanselow 1980, 1986, 1990, 2010; Kiernan and Westbrook 1993; Kiernan et al. 1995).

The interaction of the contextual learning and fear conditioning systems also explains the facilitatory effect of prior contextual learning on context-conditioned fear. Rats subjected to relatively short placement-shock intervals in a pre-exposed context freeze more when tested in that context than rats shocked at these intervals in a novel context. Exposure to the pre-exposed context activates the already formed unitary representation which enters into the association with shock, resulting in more conditioned freezing than that shown by rats shocked after short

\section{Corresponding author: f.westbrook@unsw.edu.au}

Article is online at http://www.learnmem.org/cgi/doi/10.1101//m.039065. 115. placement-context intervals in a novel context (Fanselow 1990; Kiernan and Westbrook 1993). Moreover, pre-exposure not only facilitates context fear conditioning at relatively short placement-shock intervals but also reduces generalization of this fear to similar contexts relative to the fear which generalizes when the shock occurs in a novel context (Kiernan and Westbrook 1993). Pre-exposure reduces generalization because shock conditions fear to the unitary representation formed at pre-exposure. This representation is not fully excited by exposure to other test contexts, even similar contexts containing many of the same elements but lacking the specific conjunctions of the unitary representation.

The idea that the representation of a pre-exposed context can associate with an aversive shock US has two major implications. The first is that it should be possible to condition fear to a context that has never been shocked, that is, to generate a false fear memory. The second is that manipulations which disrupt formation of the context representation in pre-exposure should impair its conditioning. Rudy and O'Reilly (1999) tested the first of these implications. They pre-exposed rats to either context A or to a control context, $\mathrm{C}$, shocked both groups of rats a few minutes after exposure to another context, B, and finally tested them in context A or context $\mathrm{B}$. Control rats pre-exposed to a very different context, $\mathrm{C}$, discriminated between contexts $\mathrm{A}$ and $\mathrm{B}$, freezing much more in context $\mathrm{B}$ than in context $\mathrm{A}$. In contrast, rats pre-exposed to context A did not discriminate between contexts $\mathrm{A}$ and $\mathrm{B}$, freezing just as much in the context which had been shocked, B, as in the context which had not been shocked but which had been preexposed, A.

The Rudy and O'Reilly (1999) results are consistent with the idea that exposure to the similar B context caused the rats to recall the pre-exposed A context whose representation was thus active when shock occurred, resulting in the formation of associations between shock and both the absent A context and the present $\mathrm{B}$

(C) 2015 Bae et al. This article is distributed exclusively by Cold Spring Harbor Laboratory Press for the first 12 months after the full-issue publication date (see http://learnmem.cshlp.org/site/misc/terms.xhtml). After 12 months, it is available under a Creative Commons License (Attribution-NonCommercial 4.0 International), as described at http://creativecommons.org/licenses/by$\mathrm{nc} / 4.0 /$. 
context. Such rats, therefore, had formed a false fear memory: they were frightened of a context, A, that had been pre-exposed but had not been shocked. However, these results could have been due to what was retrieved at test rather than what was learned at conditioning. Specifically, rats that had formed a unitary representation of the pre-exposed context A may have been better able to use this representation to retrieve the memory of the shocked context $\mathrm{B}$, thereby freezing more when tested in the pre-exposed A context than rats tested in the novel A context.

The present experiments examined false context fear memories in rats. Experiment 1 confirmed that rats shocked in context $B$ show more fear when tested in a pre-exposed A context than in a novel A context (Rudy and O'Reilly 1999). Experiment 2 used an immediate shock in context $\mathrm{B}$ to examine whether the difference in freezing between rats tested in a pre-exposed or novel A context was due to the formation of a false fear memory or to better retrieval by the pre-exposed rats. Experiment 3 examined whether testing in a pre-exposed context is sufficient to produce the false fear memory or whether it is necessary for the pre-exposure and test context to be similar to the shocked B context. Finally, as the results of Experiments 2 and 3 suggested that a false fear memory of the pre-exposed A context formed when rats were shocked in context $\mathrm{B}$, the final experiment tested the second implication of the dual process account of false fear memory: specifically, that disrupting the formation of the context representation at preexposure would impair the formation of the false fear memory.

\section{Results}

\section{Experiment 1: rats learn to fear an absent context}

In Experiment 1, rats were pre-exposed to either a distinctive chamber (context A) or a control environment (context C) on Day 1 . All rats then received two shocks in a second chamber (context B) on Day 2 (see Materials and methods). Each shock was 0.6 $\mathrm{mA}$ in intensity and $0.5 \mathrm{msec}$ in duration; parameters that produce reliable context conditioned freezing in our laboratory. Following Rudy and O'Reilly (1999), the first shock occurred 2 min after placement in B and the second shock occurred 2 min after the first. Rats remained in the context for $30 \mathrm{sec}$ after the second shock. Finally, rats were tested for freezing in the absence of shock on Day 3. Half of the rats in each group were tested in context $\mathrm{A}$ (Groups $\mathrm{ABA}$ and $\mathrm{CBA}$ ) and the remainder in context $\mathrm{B}$ (Groups ABA and ABB).

Figure 1 (left panel) shows mean and standard error of the mean (SEM) levels of freezing in 30-sec bins across conditioning in context B on Day 2 . There were no statistically significant between-group differences in the levels of freezing across the conditioning session, $F_{(3,28)}=1.4, P=0.274$, and there was no significant pre-exposure $\times$ time interaction, $F_{(24,224)}=1.1, P=$ 0.397 , demonstrating that the levels of freezing across the shocked exposure to context $\mathrm{B}$ did not differ among rats pre-exposed to context A or context C. Figure 1 (right panel) shows the mean (SEM) levels of freezing averaged across the 5-min test session in contexts A and B. Inspection suggests that rats pre-exposed to context $\mathrm{C}$ and tested in context $\mathrm{A}$ froze less than rats in the remaining groups whose levels of freezing did not appear to differ. The statistical analysis confirmed these observations. Rats pre-exposed to context $\mathrm{C}$ and tested in context A (Group CBA) froze significantly less than rats pre-exposed to context $A$ and tested in either context A or context B (Group ABA and Group ABB, respectively) and less than rats pre-exposed to context $\mathrm{C}$ and tested in context $\mathrm{B}$ (Group CBB), $F_{(1,28)}=13.826, P<0.001,95 \%$ CI $[0.478,2.558]$. There were no statistically significant differences among rats preexposed to context A or context $\mathrm{C}$ and tested in context B (Groups $\mathrm{ABB}$ and $\mathrm{CBB}$ ) or between these groups and rats pre-exposed to context $\mathrm{A}$ and tested in that context (Group ABA), $F^{\prime} \mathrm{s}<1.0$. These results replicate those reported previously (Rudy and O'Reilly 1999). Rats pre-exposed to the control context, C, showed more fear when tested in the shocked B context than in the novel A context. In contrast, rats pre-exposed to context A showed just as much fear when tested in context $B$ as in context $A$ and more fear than control rats when tested in context A.

\section{Experiment 2: rats learn to fear an absent context but not the context where shock occurred}

As noted previously, rats shocked immediately after placement in a novel context exhibit little or no fear responses when subsequently tested in that context. Experiment 2 used the immediate shock protocol to assess the consequences for the pre-exposed $\mathrm{A}$ context. If exposure to B immediately activates the unitized representation of $A$ and thereby allows that representation to enter into the association with shock, then rats pre-exposed to context $A$ and subjected to immediate shock in context B should acquire fear of A but not of B. Rats were pre-exposed to either context A or context $C$ on Day 1. As in the previous experiment, all rats received two shocks in context B on Day 2. However, in this experiment, the first shock occurred $5 \mathrm{sec}$ following placement into the context and the second shock occurred 1-sec after the first shock. Rats were kept in context B for a further $30 \mathrm{sec}$ following the second shock. Rats were tested on Day 3. Half of the rats in each group were tested in context $\mathrm{A}$ (Groups $\mathrm{ABA}$ and $\mathrm{CBA}$ ) while the remainder were tested in context $B$ (Groups $\mathrm{ABB}$ and $\mathrm{CBA}$ ).

Freezing behavior was negligible in the 30 -sec period after the immediate shock in context B $(M=1.5, S D=0.86)$ (data not shown). Figure 2 shows the levels of freezing on test in contexts $\mathrm{A}$ and $\mathrm{B}$. Inspection shows that rats pre-exposed to the control context exhibited little freezing when tested in the novel context A or in the immediately shocked context B. Likewise, rats pre-exposed to context A showed little freezing when tested in the immediately shocked context, B, but did freeze when tested in the preexposed context. The statistical analysis confirmed that there were no significant differences between the level of freezing among rats pre-exposed to contexts $\mathrm{A}$ or to $C$ and tested in context $B$, Groups $\mathrm{ABB}$ and $\mathrm{CBB}$, respectively, $F<1.0$. However, rats pre-exposed to context $\mathrm{A}$ froze significantly more when tested in context $\mathrm{A}$ (Group $\mathrm{ABA}$ ) than rats pre-exposed to the control context, C,
Figure 1. Effect of pre-exposure to the similar and control context in a standard conditioning protocol on conditioning to an absence context. $(A)$ Mean levels of freezing across 30 -sec bins as a function of experimental condition during conditioning and $(B)$ Mean percent freezing as a function of experimental condition during test. Error bars indicate standard error of the mean (SEM). 


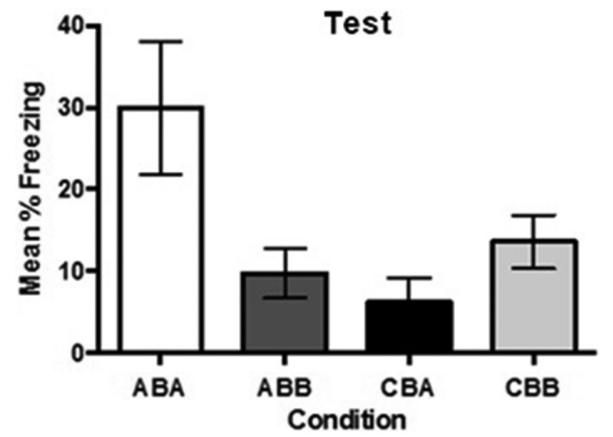

Figure 2. Effect of immediate shock during conditioning on fear to an absent context. The graph displays freezing behavior during test $24 \mathrm{~h}$ after immediate shock conditioning. Error bars represent standard error of the mean (SEM).

(Group CBA), $F_{(1,28)}=11.762, F_{\mathrm{c}}=7.2,95 \% \mathrm{CI}[0.380,3.050]$. The statistical analysis also showed that rats pre-exposed to context $\mathrm{A}$ and tested there (Group $\mathrm{ABA}$ ) froze significantly more than rats pre-exposed to contexts A or C and tested in context B (Groups $\mathrm{ABB}$ and $\mathrm{CBB}), F_{(1,28)}=9.3, F_{\mathrm{c}}=7.126,95 \%$ CI $[0.166,2.478]$. There were no statistically significant differences between the levels of freezing among rats pre-exposed to context $C$ and tested in context A (Group CBA) and rats pre-exposed to contexts A or C and tested in context $\mathrm{B}$ (Groups $\mathrm{ABB}$ and $\mathrm{CBB}$ ), $F<1.0$.

If the differences between the levels of freezing elicited by the pre-exposed and novel A context in the previous experiment had been due to better retrieval of the conditioned $B$ context by the preexposed A context, then rats pre-exposed to A in the present experiment would have exhibited little or no freezing when tested in A because B had acquired little or no conditioned fear. In contrast, if the previous results had been due to context B immediately activating the unitary representation of $A$ into an association with shock, then rats pre-exposed to context $\mathrm{A}$ in the present experiment would have formed that association and freeze when tested in that context. Just this outcome was observed: rats pre-exposed to context A and tested there froze in spite of the fact that they did not freeze when tested in the immediately shocked B context.

\section{Experiment 3: the formation of the false fear memory depends on similarity between the pre-exposed and shocked contexts}

The results of the previous experiments were interpreted to mean that the formation of the false fear memory was mediated by the similarity between the pre-exposed context, A, and the context, B, where shock occurred. An implication of this interpretation is that a false fear memory was not formed to the control context, C. Pre-exposure to context $\mathrm{C}$ would have generated a unitary representation but this representation would not have been activated by exposure to context B because the two contexts differed not only in the conjunctions characterizing each of the unitary representations but also in many of their elements. The present experiment examined this implication. The design consisted in pre-exposing rats to either the similar context A or the different context, C, on Day 1, subjecting all rats to the immediate shock in context B on Day 2, and finally testing half of the rats in each group in context $\mathrm{A}$ (Groups $\mathrm{ABA}$ and $\mathrm{CBA}$ ) and the remainder in context $\mathrm{C}$ (Groups $\mathrm{ABC}$ and $\mathrm{CBC}$ ) on Day 3. If similarity between the pre-exposed and shocked contexts mediate the false fear memory, then rats pre-exposed to context A will freeze when tested there but not when tested in the different context $C$; if a false fear memory is formed to any pre-exposed context, then rats pre- exposed to context $\mathrm{C}$ will also freeze when tested in context $\mathrm{C}$ but not when tested in context A.

There was little or no freezing subsequent to the immediate shock in context B $(M=0.98, S D=3.13)$. Figure 3 shows the test levels of freezing in contexts A and C. The statistical analysis confirmed what is clear from inspection of the figure. Rats preexposed to context A (Group ABA) froze significantly more than rats in the remaining three groups, $\mathrm{CBC}, \mathrm{CBA}$ and $\mathrm{ABC}, F_{(1,28)}=$ $24.31, P<0.001,95 \%$ CI $[0.973,3.052]$. There was no statistically significant differences between rats pre-exposed in context $\mathrm{C}$ and tested in context A (Group CBA) and rats tested in context $\mathrm{C}$ (Groups $\mathrm{ABC}$ and $\mathrm{CBC}$ ), or between rats pre-exposed to context $\mathrm{C}$ and tested there (Group $\mathrm{CBC}$ ) and rats pre-exposed to context $A$ and tested in context $\mathrm{C}$ (Group $\mathrm{ABC}$ ), $F^{\prime} \mathrm{s}<1$. These results show that similarity between the pre-exposed and shocked contexts is required for the formation of the false fear memory to the pre-exposed context.

\section{Experiment 4: an immediate shock in the pre-exposure session impairs formation of a false fear memory}

As noted previously, pre-exposure to a context can facilitate the development of freezing responses when rats are shocked in that context. However, an immediate shock in each of the pre-exposure sessions attenuated this facilitatory effect of context pre-exposure on the development of freezing when rats were subsequently shocked after a delay in that context (LandeiraFernandez et al. 2006). This attenuation of the context preexposure facilitatory effect suggests that the immediate shock had impaired the formation of the unitary representation which mediates the facilitatory effect of context pre-exposure on context fear conditioning. Consistent with this suggestion, rats that received an immediate shock followed $170 \mathrm{sec}$ later by a second shock froze less when tested in that context than rats that received the first shock at $150 \mathrm{sec}$ followed by the second shock at $170 \mathrm{sec}$, again suggesting that the immediate shock had impaired the subsequent formation of the unitary representation, and thereby, the association formed between that representation and the second shock, resulting in the reduction in context fear conditioning (Westbrook et al. 1994).

The present experiment examined whether the formation of the false fear memory to context A is also impaired when the preexposure session begins with an immediate shock. The design consisted in pre-exposing rats to context A on Day 1, subjecting them to immediate shock in context B on Day 2, and finally testing all rats in context A on Day 3. There were two differences among the groups. The first was the duration of pre-exposure to context A, which was either 2 min for two of the groups and 4

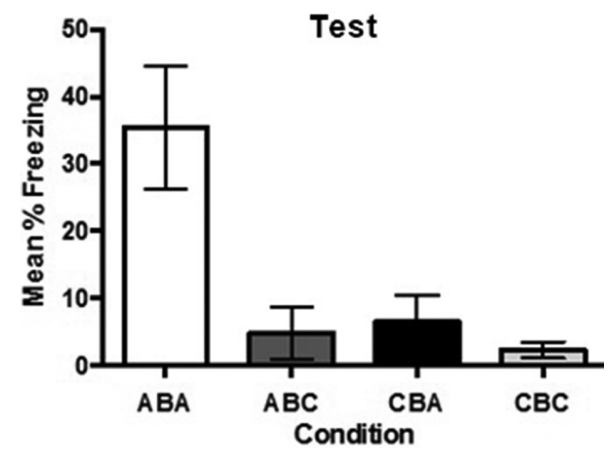

Figure 3. Effect of similarity between the pre-exposed and shocked context on fear to an absent context. Mean percent freezing as a function of experimental condition during test $( \pm$ SEM). 
min for the other two groups. The second difference was that the 2 or 4 min pre-exposure in context A began with an immediate shock for half of the rats in each group (Groups A2 shock and A4 shock) but there was no shock in the other two groups (Groups A2 and A4).

One rat in group A2 became sick and was excluded from the experiment. There was little or no freezing subsequent to the immediate shock in context A or subsequent to the immediate shock in context $\mathrm{B}(M=1.2, \mathrm{SD}=2.58$ and $M=0.47, \mathrm{SD}=1.05$, respectively). Figure 4 shows the levels of freezing on test in context A. The statistical analysis confirmed what is clear from inspection. First, rats pre-exposed to context A for $4 \mathrm{~min}$ (Groups A4 and A4 shock) froze significantly more than rats pre-exposed for 2 min (Groups A2 and A2 shock), $F_{(1,27)}=5.6, P<0.05,95 \% \mathrm{CI}$ $[-1.586,-0.110]$. This difference in the test levels of freezing indicates that the 4-min pre-exposure had produced a rich representation of context $A$ and hence one that was better able to associate with the immediate shock in context $B$ than the sparse representation produced by the 2-min pre-exposure. Second, rats whose preexposure in context A had begun with immediate shock (Groups A2 shock and A4 shock) froze significantly less than those that were pre-exposed to context A in the absence of shock (Groups $\mathrm{A} 2$ and $\mathrm{A} 4), F_{(1,27)}=5.368, P<0.05,95 \% \mathrm{CI}[-1.572,-0.095]$, indicating that the immediate shock had impaired the formation of the unitary representation across the subsequent 2 and 4 min in context A. There was no significant interaction, $F<1$, indicating that the disruptive effects of the immediate shock were independent of whether the rats remained in that context for 2 or 4 min.

\section{Discussion}

The results of these experiments have shown that rats fear a context in which they have never experienced danger, and that this fear is due to the formation of a false association between this context and danger encountered elsewhere. Rats pre-exposed to one context, A, and shocked after a delay in a second context, B, exhibited just as much fear (freezing) when tested in the pre-exposed A context as in the shocked B context. In contrast, control rats shocked in context B froze just as much as the pre-exposed rats when subsequently tested in B but froze less than the pre-exposed rats when tested in the novel context $\mathrm{A}$. This difference between the levels of freezing in the pre-exposed and novel A contexts was not due to differential retrieval of the frightening context $B$ when rats were tested in $\mathrm{A}$. Control rats subjected to an immediate

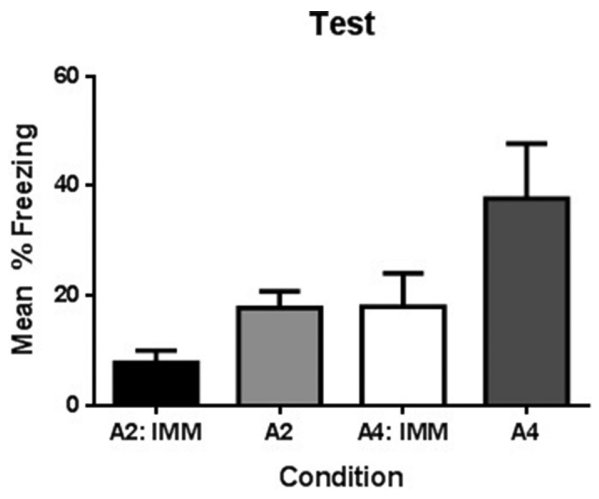

Figure 4. Effect of immediate shock in pre-exposure session on subsequent false memory formation. Mean percent freezing as a function of experimental condition during test. All rats received a single exposure session to similar context $(A)$. Some were exposed for 2 min (Groups A2: imm and A2) while others for 4 min (Groups A4: imm and A4). Error bars represent standard error of the mean (SEM). shock in context B did not freeze when tested in either the novel context A or in context B; they showed the immediate shock fear deficit. Rats pre-exposed to context A and subjected to an immediate shock in context B also exhibited the immediate shock fear deficit; they did not freeze when tested in that context. However, in spite of the fact that the immediate shock failed to condition fear of context $\mathrm{B}$, that shock did condition fear to the pre-exposed A context. Therefore, fear of the pre-exposed context A cannot be due to retrieval of the frightening B context because that context was not frightening.

Moreover, the difference in freezing in the pre-exposed and novel A contexts was not due to testing rats in a pre-exposed context per se: the difference was contingent on similarity between the pre-exposed and shocked contexts. In each of the present experiments, contexts A and B were similar to each other in their size, shape, surfaces, and floor, while both of these contexts were different from context $\mathrm{C}$ in these various features (see Apparatus for description of contexts). Rats pre-exposed to context $C$ and subjected to immediate shock in context $\mathrm{B}$ did not freeze when subsequently tested in context $\mathrm{C}$ or the novel context $\mathrm{A}$, whereas rats pre-exposed to context $\mathrm{A}$ froze when tested in that context but did not freeze when tested in context $\mathrm{C}$. Together with the previous results, this finding implies that fear of the pre-exposed A context was not due to any interaction between the conditions of pre-exposure and testing; rather, fear of the pre-exposed A context was acquired when rats were subjected to the immediate shock in context B. Specifically, overlap among the features of the A and B contexts meant that the unitary representation of context $A$ was activated during the shocked exposure to context B, and hence, entered into an association with the immediate or the delayed shock in context B. In contrast, there was no such activation of the pre-exposed $\mathrm{C}$ context because the features in $\mathrm{B}$ did not overlap with those in context $\mathrm{C}$ and, hence, there was no formation of a false fear memory of context $C$.

Of course, overlap among the features of the A and B contexts should only permit conditioning of a false fear memory of context A if rats developed a unitary representation of A in pre-exposure. The final experiment used an immediate shock in the pre-exposed context A to distinguish between pre-exposure per se and the unitary representation normally formed at that pre-exposure in producing the false fear memory. This experiment showed that a longer $(4 \mathrm{~min})$ pre-exposure to context $\mathrm{A}$ resulted in a stronger false fear memory than a shorter $(2 \mathrm{~min})$ duration, indicating that the duration of pre-exposure regulates the richness of the unitary representation and hence its associability with the immediate shock in context B. Critically, the immediate shock in context B produced a weaker false fear memory of the pre-exposed A context among rats whose pre-exposure to context A began with an immediate shock than rats pre-exposed in the absence of that shock. This disruption was observed when the duration of the preexposure was short $(2 \mathrm{~min})$ and longer $(4 \mathrm{~min})$, and the degree of disruption in the false memory was independent of the duration of pre-exposure, indicating that the immediate shock suppresses the processing of the contextual array into the unitary representation which enters into the association with the immediate shock in context $\mathrm{B}$, mediating the false fear memory. The formation of the unitary representation is therefore critical for the false fear memory of the pre-exposed context just as that representation is critical for the formation of a true fear memory of a shocked context (e.g., Fanselow 1980).

These findings suggest something of a paradox: rats learn to fear a context in which they have "never" been shocked, but this learning is disrupted if rats are "actually" shocked in that context. However, they are exactly those anticipated by a dual systems model of context fear conditioning. According to this model, encoding of a context representation and its association with shock 
are separable processes with distinct neural substrates: the hippocampus, but not amygdala, is involved in processing the conjunctions among the array of contextual cues; the amygdala, but not the hippocampus, is involved in associating the output of the hippocampal system with the aversive shock US. Hence, the hippocampus and amygdala combine in the generation of a true context fear memory. It is likely that they also combine in the generation of the false fear memory of the pre-exposed A context. In fact, a recent computational model [Bayesian Context Fear Algorithm/Automaton (BACON)] of the neural substrates underlying context fear conditioning makes explicit that exposure to the novel context $\mathrm{B}$ confronts the subject with the task of deciding whether the contextual cues sampled are from a familiar context or a novel context requiring a new representation (Krasne et al. 2015). According to this model, exposure to the similar B context immediately and progressively activates elements of the already formed representation of the pre-exposed A until discrepancies between that representation and the currently sampled contextual cues generate the process that constructs the new representation of context B. This model thus predicts that shock in B will condition fear of the pre-exposed A across a range of placement-shock intervals: specifically, fear will accrue to A in the absence of fear of B (the immediate shock protocol used in Experiments 2-4 and when fear has accrued to B (the delayed shock used in Experiment 1); but fear will not accrue to A when the new representation of B is sufficiently developed (e.g., with a sufficiently long placement-shock interval in B).

Ramirez and colleagues (2013) have provided direct evidence of the role played by the hippocampus in the creation of a false context fear memory. These investigators used optogenetic techniques to create a false context fear memory. Hippocampal neurons active while rats explored a novel context (A) were labeled with channelrhodopsin-2 (ChR2), a light-gated cation channel. ChR2 responds to blue light by depolarizing the labeled cell, ultimately causing an action potential. Thus, neurons activated during pre-exposure (context A neurons) could be artificially reactivated via blue-light stimulation. Ramirez et al. (2013) reactivated context A neurons by blue-light stimulation when rats received a shocked exposure to a second, different context B. They found that these rats froze when subsequently tested in B or A, whereas control rats shocked in $\mathrm{B}$, in the absence of the blue-light stimulation of context A neurons, subsequently froze in B but not in A. In the present experiments, exposure to the similar context B functioned like the artificial activation of the ensemble of cells coding the unitary representation of the pre-exposed A context; activation that enabled these cells to enter into the association with shock via hippocampal-amygdala pathways.

While the hippocampus and amygdala play complementary roles in the formation of both true and false context fear memories, the results of the final experiment are consistent with the proposal that activation of the amygdala by the shock US inhibits hippocampal processing of the unitary representation of context (O'Reilly and Rudy 2001). Consistent with such inhibition, the number of hippocampal cells expressing the fos protein of the immediate early gene (IEG), c-fos, was less in rats subjected to immediate shock than in rats not shocked or rats shocked after a delay, whereas the number of amygdala cells expressing the fos protein was higher in both groups of shocked rats than in the nonshocked control rats (Milanovic et al. 1998). The disruptive effect of the immediate shock on contextual processing may reflect changes in attention to specific features of the environment, which are mediated through interactions between the amygdala and cortical sensory processing regions (Phelps and LeDoux 2005). On the one hand, there is considerable evidence that the amygdala facilitates attention toward emotional information (Whalen et al. 1998; Ohman et al. 2001; Fox 2002; Phelps and
LeDoux 2005). On the other hand, evidence from "emotioninduced blindness" studies shows that the presentation of an emotional image impairs the ability of human participants to recall subsequently presented images (Most et al. 2005, 2006; Smith et al. 2006). Such findings show that emotional stimuli capture attention but also impair subsequent information processing. Indeed, fMRI studies report that attention to an emotional distractor is correlated with increased amygdala activity, providing support for the notion that activation of the amygdala may be critical for disruption of subsequent processing of environmental information (Most et al. 2006).

A recent report by Lovett-Barron et al. (2014) has suggested an alternative route by which the aversive shock US may have impaired the hippocampal processing of contextual information. These investigators demonstrated local inhibition of hippocampal CA1 pyramidal neurons by somatostatin-positive interneurons during aversive US presentations. This inhibition is thought to attenuate contextual fear learning by blocking information conveying discrete sensory properties of the context from the entorhinal cortex. Thus, rather than, or in addition to the role of the amygdala in regulating the disruptive effect of the immediate shock on false and true fear memories, another mechanism by which the US presentation impairs the generation of a contextual representation may be within the hippocampus itself.

Finally, it is worth noting the considerable evidence that people remember events that did not happen or did not happen in the way that they are remembered (Mather et al. 1997; Schacter 1999). For example, it is now well-documented that individuals have been found guilty of violent crimes that they did not commit based on the honest but false testimonies of victims. The conditions under which such testimonies are typically obtained have led to various proposals concerning the roles of suggestion and social factors in the recollective processes that can produce false memories in victims (and eye-witnesses) (Loftus and Pickrell 1995). There are likely many processes involved, but the present results suggest that false fear memories can also be formed when the crime is committed. If a perpetrator whose identity is obscured but nevertheless sufficiently detected to activate the memory of a similar but absent person at the time of a crime, the memory of the absent person can enter into the associative network formed by the frightening experience, just as context B produces the false memory of context $\mathrm{A}$ in the present experiments.

\section{Materials and Methods}

\section{Subjects}

The subjects were experimentally naïve, male Sprague-Dawley rats (Rattus norvegicus), aged between 7 and $11 \mathrm{wk}$, weighing between 270-410 g, and obtained from the Animal Resources Centre (Perth, Western Australia). Rats were housed in groups of eight in plastic boxes $(67-\mathrm{cm}$ length $\times 40$-cm width $\times 22$-cm height) located in a colony room maintained at $20^{\circ} \mathrm{C}$ whose lights were turned on at 7.00 a.m. and off at $7.00 \mathrm{p} . \mathrm{m}$. All experimental procedures occurred between 1:00 and 3:00 p.m. All rats had ad libitum access to food and water. Each rat was handled for 5-min per day for $7 \mathrm{~d}$ prior to the start of the experiment. Rats were treated in accordance with the Australian National Health and Medical Research Council guidelines, and all procedures were approved by the Animal Care and Ethics Committee of The University of New South Wales.

\section{Apparatus}

Pre-exposure was conducted in either context A or context C. Context A shared features with the shocked context, B, and fear conditioned to context B generalizes to context A (e.g., Kiernan and Westbrook 1993). Context A consisted of two 
chambers, each measuring $25-\mathrm{cm}$ in length, $30-\mathrm{cm}$ in width, and $25-\mathrm{cm}$ in height. The front and back walls were made of clear Perspex and the sidewalls and ceiling were made of aluminum. The floor consisted of stainless steel rods, $8-\mathrm{mm}$ in diameter and spaced 12-mm apart. A removable stainless steel waste tray containing corncob bedding (Able Scientific, Sydney) was located 3 -cm below the stainless steel rods. The bedding was changed after the removal of each rat. A video camera, mounted on the back wall of each chamber, recorded the behavior of each rat. Each camera was connected to a DVD recorder and monitor located in another room in the laboratory. The chambers were located on the roof of a wooden cabinet containing the shocked chambers (Context B).

The second pre-exposure chamber, $\mathrm{C}$, consisted in two plastic white opaque buckets with lids, each measuring $30-\mathrm{cm}$ height $\times 20$-cm diameter, located in another room in the laboratory. In experiment 3 , context $C$ consisted in a single plastic cage (46-cm length $\times 32$-cm width $\times 17-\mathrm{cm}$ height) located in a different room to that of the A and B contexts. The plastic cage was placed inside a wooden cabinet whose walls, floors and ceilings were covered in white wallpaper. The door of the cabinet was left open throughout the duration of the experiment. The roof of the cage consisted in a removable stainless steel grid, and the floor and three sides were made of black plastic. The remaining side, made of clear Perspex, faced the camera mounted on the back wall of the wooden compartment. The camera was connected to a DVD recorder and monitor located in another room in the laboratory. The floor and sidewalls were cleaned with water after removal of each rat.

The shocked context, B, consisted in four identical chambers (25-cm length $\times 30$ - $\mathrm{cm}$ width $\times 28$ - $\mathrm{cm}$ height) located in separate compartments of a wooden cabinet whose walls, floors and ceilings were painted black. Like the chambers designated as context $\mathrm{A}$, the sidewalls of the chambers designated as context B were aluminum and the front, back and ceiling were made of clear Perspex. The floors of the chambers used for context $B$, like those of the chambers for context A, consisted of stainless steel rods spaced 12-mm apart but were, 2-mm in diameter (rather than the 8-mm in context A). A removable stainless steel tray containing the same corncob bedding material as in the chambers of context A was located below the floor of each chamber. After removal of each rat, the bedding was changed and the sidewalls and floor was cleaned with water. Illumination for each chamber was provided by an infrared light source $(940 \pm 25 \mathrm{~nm})$. A camera mounted on the back wall of the wooden compartment facing the chambers was connected to a DVD recorder and monitor located in another room in the laboratory. No distinguishing odors were used in any context and all rats were carried from their home cages their respective contexts (A, B, or C) across all stages of the experiment (Pre-exposure, Conditioning and Test).

The aversive US in all experiments was a $0.5 \mathrm{sec}, 0.6-\mathrm{mA}$ scrambled footshock delivered through the grid floor. An ammeter was used to ensure correct current through the grid floor prior to conditioning. The chambers were connected to a computer installed with MATLAB (MathWorks) software that controlled shock administration.

\section{Procedures}

\section{Pre-exposure}

In Experiments 1-3, rats received a single 4-min exposure session to their respective contexts on Day 1. In Experiment 4, rats also received a single pre-exposure session whose duration was 2-min for half of the rats and 4-min for the remainder. Those in the immediate shock pre-exposure conditions (Groups A2: shock and A4: shock) received a single shock immediately upon placement into the context.

\section{Conditioning}

On Day 2, all rats were placed in Context B and received two shocks. In Experiment 1, the first shock was delivered 2-min fol- lowing placement into the chamber and the second 2-min after the first shock. In Experiments 2-4, the first shock occurred 5 -sec after placement in the chamber and the second occurred 1-sec following the delivery of the first shock. Two shocks were given in Experiment 1 in order to replicate the findings of Rudy and O'Reilly (1999). Furthermore, in order to maintain consistency across experimental designs, all experiments thereafter also used two shocks. In all experiments, rats were kept in B for a further 30-sec following the second shock before being removed and returned to their home cages in the colony room.

\section{Test}

On Day 3, all rats were tested in their respective contexts, A or B, and $\mathrm{A}$ or $\mathrm{C}$ in Experiment 3. The test lasted for $5 \mathrm{~min}$ in duration and no shock was presented.

\section{Data collection and analysis}

A time sampling procedure was used in which each rat was scored as either freezing or not freezing every $2 \mathrm{sec}$. Freezing was defined as the absence of all movement, except that necessary for breathing (Fanselow 1980). Freezing was cross-scored by an observer blind to the experimental conditions, and an observed correlation $>0.90$ was obtained for all experiments. Any differences between the two observers were resolved in favor of the one blind to the experimental conditions. Overall differences between groups across the shocked exposure to context B were analyzed using repeated-measures ANOVA (Experiment 1) or one-way ANOVAs (Experiments 2-4). The test data were analyzed with planned contrasts for Experiments 1-3 and a two-way ANOVA for Experiment 4. In cases where the sets of contrasts were orthogonal, the Per Contrast Error Rate was set at 0.05, and for sets of nonorthogonal contrasts, a Bonferroni correction was used to control the Per Family Error rate at 0.05 .

\section{Acknowledgments}

This research was supported by an Australian Research Council Discovery Project grant.

\section{References}

Davis M. 1990. Animal models of anxiety based on classical conditioning: the conditioned emotional response (CER) and the fear-potentiated startle effect. Pharmacol Ther 47: 147-165.

Fanselow MS. 1980. Conditional and unconditional components of post-shock freezing in rats. Pavlov J Biol Sci 15: 177-182.

Fanselow MS. 1986. Associative versus topographical accounts of the immediate shock-freezing deficit in rats: implications for the response selection rules governing species-specific defensive reactions. Learn Motiv 17: 16-39.

Fanselow MS. 1990. Factors governing one-trial contextual conditioning. Anim Learn Behav 18: 264-270.

Fanselow MS. 2010. From contextual fear to a dynamic view of memory systems. Trends Cogn Sci 14: 7-15.

Fox E. 2002. Processing emotional facial expressions: the role of anxiety and awareness. Cogn Affect Behav Neurosci 2: 52-63.

Kiernan MJ, Westbrook RF. 1993. Effects of exposure to a to-be-shocked environment upon the rat's freezing response: evidence for facilitation, latent inhibition, and perceptual learning. Q J Exp Psychol B 46: $271-288$.

Kiernan MJ, Westbrook RF, Cranney J. 1995. Immediate shock, passive avoidance, and potentiated startle: implications for the unconditioned response to shock. Anim Learn Behav 23: 22-30.

Krasne FB, Cushman JD, Fanselow MS. 2015. A Bayesian context fear learning algorithm/automaton. Front Behav Neurosci 9: 112.

Landeira-Fernandez J, Kim JJ, DeCola JP, Fanselow MS. 2006. Immediate shock deficit in fear conditioning: effects of shock manipulations. Behav Neurosci 120: 873-879.

Loftus EF, Pickrell JE. 1995. The formation of false memories. Psychiatr Ann 25: 5 . 
Lovett-Barron M, Kaifosh P, Kheirbek MA, Danielson N, Zaremba JD, Reardon TR, Losonczy A. 2014. Dendritic inhibition in the hippocampus supports fear learning. Science 343: 857-863.

Mather M, Henkel LA, Johnson MK. 1997. Evaluating characteristics of false memories: remember/know judgments and memory characteristics questionnaire compared. Mem Cognit 25: 826-837.

McLaren IPL, Kaye H, Mackintosh NJ. 1989. An associative theory of the representation of stimuli: applications to perceptual learning and latent inhibition. In Parallel distributed processing: implications for psychology and neurobiology (ed. Morris RGM ), pp. 102-130. Oxford University Press, Oxford, UK.

Milanovic S, Radulovic J, Laban O, Stiedl O, Henn F, Spiess J. 1998. Production of the fos protein after contextual fear conditioning of C57BL/6N mice. Brain Res 784: 37-47.

Most SB, Chun MM, Widders DM, Zald DH. 2005. Attentional rubbernecking: cognitive control and personality in emotion-induced blindness. Psychon Bull Rev 12: 654-661.

Most SB, Chun MM, Johnson MR, Kiehl KA. 2006. Attentional modulation of the amygdala varies with personality. Neuroimage 31: $934-944$.

Ohman A, Flykt A, Esteves F. 2001. Emotion drives attention: detecting the snake in the grass. J Exp Psychol Gen 130: 466-478.

O'Reilly RC, Rudy JW. 2001. Conjunctive representations in learning and memory: principles of cortical and hippocampal function. Psychol Rev 108: $311-345$.
Phelps EA, LeDoux JE. 2005. Contributions of the amygdala to emotion processing: from animal models to human behavior. Neuron 48 : $175-187$.

Ramirez S, Liu X, Lin PA, Suh J, Pignatelli M, Redondo RL, Ryan TJ, Tonegawa S. 2013. Creating a false memory in the hippocampus. Science 341: $387-391$.

Rudy JW, O'reilly RC. 1999. Contextual fear conditioning, conjunctive representations, pattern completion, and the hippocampus. Behav Neurosci 113: 867-880.

Schacter DL. 1999. The seven sins of memory. Insights from psychology and cognitive neuroscience. Am Psychol 54: 182.

Smith SD, Most SB, Newsome LA, Zald DH. 2006. An emotion-induced attentional blink elicited by aversively conditioned stimuli. Emotion 6: $523-527$.

Sutherland RJ, Rudy JW. 1989. Configural association theory: the role of the hippocampal formation in learning, memory, and amnesia. Psychobiology 17: 129-144.

Westbrook RF, Good AJ, Kiernan MJ. 1994. Effects of the interval between exposure to a novel environment and the occurrence of shock on the freezing responses of rats. Q J Exp Psychol B 47: 427-446.

Whalen PJ, Rauch SL, Etcoff NL, McInerney SC, Lee MB, Jenike MA. 1998. Masked presentations of emotional facial expressions modulate amygdala activity without explicit knowledge. J Neurosci 18: 411-418.

Received May 14, 2015; accepted in revised form July 24, 2015. 


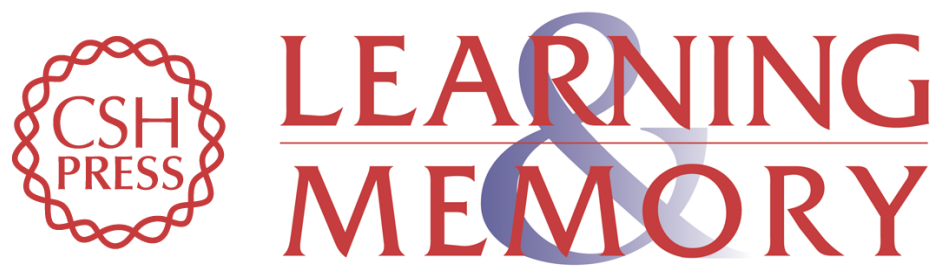

\section{False context fear memory in rats}

Sarah E. Bae, Nathan M. Holmes and R. Frederick Westbrook

Learn. Mem. 2015, 22:

Access the most recent version at doi:10.1101/lm.039065.115

References This article cites 26 articles, 3 of which can be accessed free at: http://learnmem.cshlp.org/content/22/10/519.full.html\#ref-list-1

Creative This article is distributed exclusively by Cold Spring Harbor Laboratory Press for the Commons first 12 months after the full-issue publication date (see

License http://learnmem.cshlp.org/site/misc/terms.xhtml). After 12 months, it is available under a Creative Commons License (Attribution-NonCommercial 4.0 International), as described at http://creativecommons.org/licenses/by-nc/4.0/.

Email Alerting Receive free email alerts when new articles cite this article - sign up in the box at the Service top right corner of the article or click here. 